\title{
Ontogenetic and environmental effects on otolith shape variability in three Mediterranean European eel (Anguilla anguilla, L.) local stocks
}

\author{
Fabrizio Capoccioni ${ }^{\mathrm{a}, *}$, Corrado Costa ${ }^{\mathrm{b}}$, Jacopo Aguzzi ${ }^{\mathrm{c}}$, Paolo Menesatti ${ }^{\mathrm{b}}$, \\ Antoni Lombarte ${ }^{\mathrm{c}}$, Eleonora Ciccotti ${ }^{\mathrm{a}}$ \\ a Dipartimento di Biologia, Università degli Studi di Roma “Tor Vergata", via della Ricerca Scientifica snc, 00133 Rome, Italy \\ ${ }^{\mathrm{b}}$ CRA-ING (Agricultural Engineering Research Unit of the Agriculture Research Council) Via della Pascolare, 16, 00015, Monterotondo Scalo (Rome), Italy \\ c Institut de Ciències del Mar (ICM-CSIC). Passeig Marítim de la Barceloneta 37, 08003 Barcelona, Catalonia, Spain
}

\section{A R T I C L E I N F O}

\section{Article history:}

Received 27 July 2010

Received in revised form 11 November 2010

Accepted 15 November 2010

\section{Keywords:}

Anguilla anguilla

Elliptic Fourier analysis

Habitat related changes

Otolith shape

Size-shape relationshipe

\begin{abstract}
A B S T R A C T
Otolith morphology is an efficient tool for the discrimination of fish stocks, populations and species when comparative genetic data are not available. Currently, the relationship between environmental factors and otolith shape is poorly characterized for the European eel (Anguilla anguilla), a highly migratory catadromous species constituting a single, randomly mating stock. The present study analyses the differences in otolith morphology between three Mediterranean eel local stocks from different environmental contexts (i.e. two brackish lagoons and one river). The relationship between otolith shape and otolith size was studied by means of Elliptic Fourier analysis and multivariate statistics. Otolith profile was digitally acquired and Cartesian coordinates were extracted. Partial Least Square (PLS) analysis pointed to continuous allometric growth in size and shape in otoliths from all three sites. In the three environments, shape variations occurred during growth as indicated by the presence of a significant and positive relationship between otolith size and the first PLS latent vector (i.e. which bears most of the information regarding otolith outline). Differences between smaller and larger sized otoliths were investigated using PLS Discriminant Analysis (PLSDA) and cluster analysis. Results indicate that otolith shape is highly uniform at smaller than at larger sizes. These shape differences apparently overlap the initial differentiation of the small otolith outlines acquired by eels during the growing phase as elvers in the marine environment. Data were discussed considering that the physical and chemical habitat variability in brackish lagoons and river could underlie a marked change in otolith shape during the animals' growth.
\end{abstract}

(c) 2010 Elsevier B.V. All rights reserved.

\section{Introduction}

The otoliths are calcium carbonate concretions in the inner ear of fish. The saccular otolith (sagitta) is characterized by high morphological variability between species (Platt and Popper, 1981). Endogenous and exogenous factors determine both otolith overall shape and growth patterns (Lombarte et al., 2003). Otoliths can be considered as permanent recorders of the exposure of animals to combinations of environmental factors (Jones, 1992). Otolith morphology provides an efficient tool for distinguishing between fish stocks, populations and species when comparative genetic data are not available (Castonguay et al., 1991; Lombarte and Castellon, 1991; Campana and Casselman, 1993; Cardinale et al., 2004; Stransky et al., 2005). They function as good phenotypic markers that can be used to study environmentally-induced variations (i.e. the reaction norm), acting as more effective tools than the genetic variation itself in the fishery management of endangered species (Begg et al., 1999).

\footnotetext{
* Corresponding author. Fax: + 390672595965.

E-mail address: fabrizio.capoccioni@uniroma2.it (F. Capoccioni).
}

The peculiar chronological and chemical properties of otoliths form the basis of numerous studies focused on their organic and inorganic composition which is dependent on the animals' continuous presence in certain water masses, thus allowing the characterization of individual life history as a function of the use made of the habitat at different growth stages (Elsdon et al., 2008). Otolith chemistry has been studied for the purpose of tracking movements and/or habitat shifts throughout life history (Tzeng et al., 1997, 2005; Daverat et al., 2005), hence inferring stock structure and population connectivity (Stransky et al., 2005). This is the case of the catadromous species Anguilla anguilla (L.), (i.e. the European eel). This species presents a highly migratory behaviour, spawning in the Sargasso Sea and growing in all types of Northern and Western European freshwater habitats as well as in the Mediterranean Sea. European eel panmixia theory is generally accepted, and, although has been debated for long time (e.g. Wirth and Bernatchez, 2001; Bianchini et al., 2009), it asserts that all European eels constitute a single, randomly mating stock (Dannewitz et al., 2005). So far only one study has focused on the relationship between environmental factors and otolith morphology in the A. anguilla, highlighting that eels infected by Anguillicola crassus, a swimbladder 
parasite, presented shape differences between right and left otolith with respect to sane specimen (Sahyoun et al., 2008).

The understanding and characterization of the otolith shape in European eel local stocks is of interest since somatic plasticity may not be related to genetic differentiation, but could be totally dependent on factors related to habitat characteristics (e.g. latitude, temperature, salinity, food supply) and other demographic features (e.g., population density and population size)(Vøllestad, 1992; Melià et al., 2006; Bevacqua et al., 2006). All these factors seem to influence overall body growth (De Leo and Gatto, 1995).

In this context, for the first time we analyzed the intra- and interpopulation phenotypic plasticity of otolith morphology in three Mediterranean eel stocks from different environments (i.e. coastalmarine and inland freshwater areas). We investigated the morphological change in otolith shape during the growth, thus targeting the relationship between size and shape. Morphological changes were analyzed in relation to the juvenile-adult transition (i.e. at the recruitment from the sea to inland water systems up to the subsequent reproductive migration). Elliptic Fourier analysis (Castonguay et al., 1991; Stransky et al., 2005), combined with multivariate statistics (i.e. PLS and PLSDA; Costa et al., 2009, 2010) was used to distinguish otoliths according to their contour.

\section{Materials and methods}

\subsection{Sampling sites}

The animals used in the present study were sampled by fyke netting in three different sampling locations in central and southern Italy. Sampling sites were chosen on the basis of marked ecological differences and fishery exploitation pressure (Table 1): a) the lower reaches of the Tiber river (TEV; central Tyrrhenian coast), b) the Caprolace lagoon (CAP; Circeo National Park, central Tyrrhenian coast); and finally, c) the Lesina lagoon (LES; Gargano National Park, southern Adriatic coast) (Fig. 1).

The river Tiber is the longest river in Central Italy, rising in the Apennine Mountains and flowing $405 \mathrm{~km}$ to the Tyrrhenian Sea. The study area was situated $20 \mathrm{~km}$ from the river mouth and may be considered a freshwater habitat as it is reported to have a salinity of 0 in all seasons. During the year, the mean water temperature is $17.2^{\circ} \mathrm{C}$ (min $10^{\circ} \mathrm{C}$, max $23.7^{\circ} \mathrm{C}$ ). The sampling area coincides with the lower river reaches, downstream from the city of Rome, which receives a number of canals draining farmland (Solimini et al., 2000) that contribute a high organic input. Caprolace is part of the coastal Pontine lagoon system in Central Italy, which has been included in the Ramsar List of Wetlands of International Importance since 1978. It is $2.26 \mathrm{~km}^{2}$ wide, with an average depth of $1.3 \mathrm{~m}$ ( $2.9 \mathrm{~m}$ maximum). In order to reduce pollutant load, watercourses bearing agriculture land drainage inputs were deviated in the late 70's (Prato et al., 2009). The salinity of the basin system consequently often exceeds 40 during the summer. The brackish coastal lagoon of Lesina has a surface area of $51.4 \mathrm{~km}^{2}$, with a mean water depth of $1 \mathrm{~m}$. A permanent flow from east to west generates a salinity gradient that varies between 10.6 and 28.4. Freshwater inputs come from several springs (SOGESID, 2002). Temperatures in both lagoons vary annually between 10 and $30{ }^{\circ} \mathrm{C}$.

\subsection{Data acquisition and treatment}

The otoliths of 140 specimens caught during fishing season 2007/08 were collected for each sample. The analysis was done on yellow and silver eels ranging in size from $20 \mathrm{~cm}$ to $72 \mathrm{~cm}$. The right sagitta was photographed (Microscope Stemi SV 6; Zeiss and Camera ProcRes C-10)

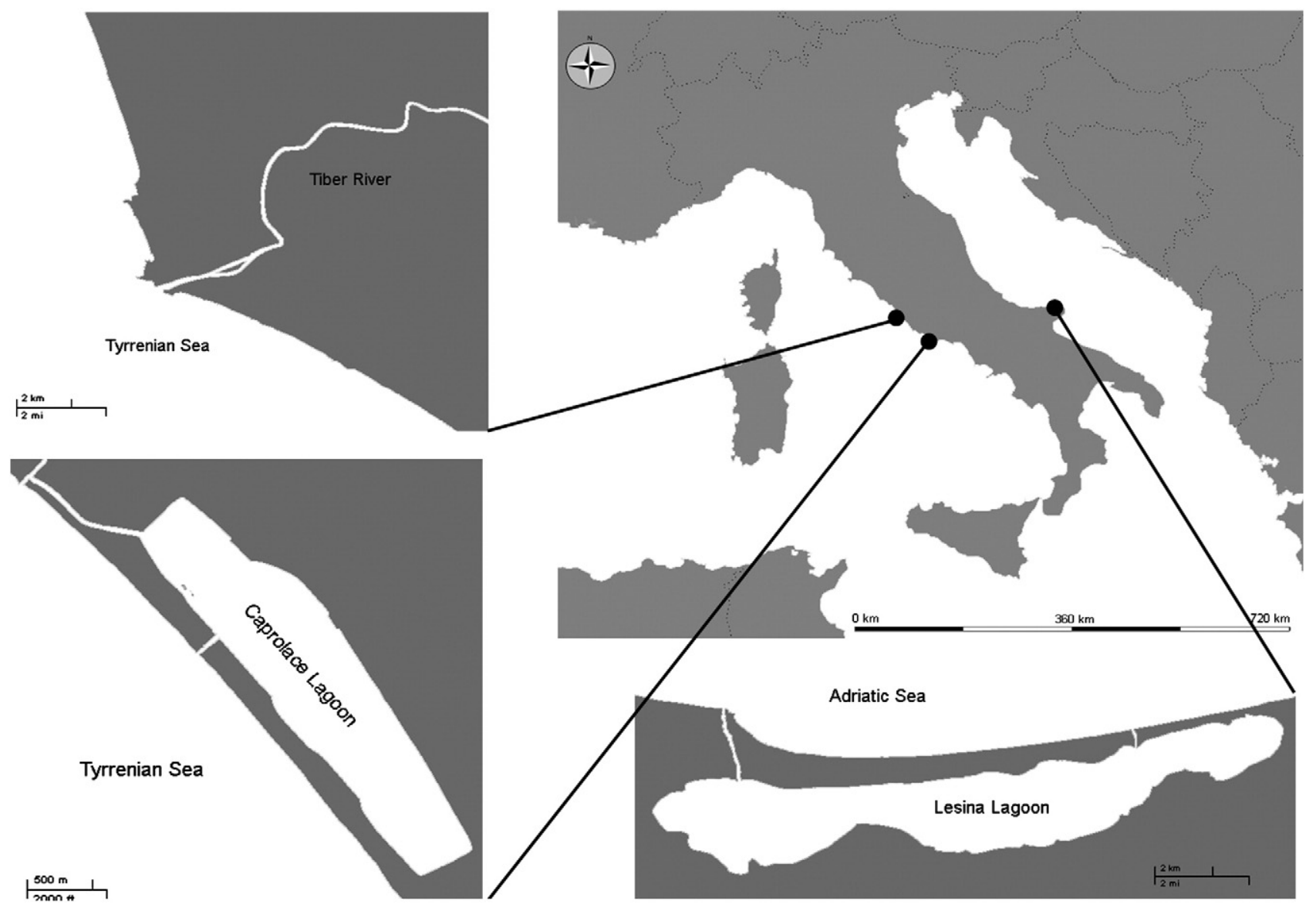

Fig. 1. Map. The three different locations of sampling sites selected in Italy. 
Table 1

Habitat characteristics of selected sample sites (Tiber river-TEV; Caprolace lagoon-CAP; Lesina lagoon-LES).

\begin{tabular}{|c|c|c|c|c|c|c|c|c|}
\hline Site & $\begin{array}{l}\text { Geographic coordinates } \\
\text { (lat. and long.) }\end{array}$ & $\begin{array}{l}\text { Area } \\
\left(\mathrm{km}^{2}\right)\end{array}$ & $\begin{array}{l}\text { Average } \\
\text { depth }(\mathrm{m})\end{array}$ & $\begin{array}{l}\text { Average salinity } \\
\text { (psu) }\end{array}$ & $\begin{array}{l}\text { Salinity range } \\
\text { (psu) }\end{array}$ & $\begin{array}{l}\text { Average } \\
\text { temperature }\left({ }^{\circ} \mathrm{C}\right)\end{array}$ & $\begin{array}{l}\text { Temperature } \\
\text { range }\left({ }^{\circ} \mathrm{C}\right)\end{array}$ & $\begin{array}{l}\text { Hydrographical } \\
\text { ituation }\end{array}$ \\
\hline TEV & $\begin{array}{l}41^{\circ} 47^{\prime} 57.89 " \mathrm{~N} \\
12^{\circ} 23^{\prime} 56.40^{\prime \prime} \mathrm{E}\end{array}$ & 10 (km; course length) & 6.5 & 0 & - & 17.2 & $10-23.7$ & Outside the salt wedge \\
\hline CAP & $\begin{array}{l}41^{\circ} 20^{\prime} 51.85^{\prime \prime N} \\
12^{\circ} 58^{\prime} 34.10^{\prime \prime} \mathrm{E}\end{array}$ & 2.26 & 1.3 & 39 & $32.4-42.9$ & 20.3 & $11-32$ & 2 sea canal, no freshwater inputs \\
\hline LES & $\begin{array}{l}41^{\circ} 53^{\prime} 8.34^{\prime \prime} \mathrm{N} \\
15^{\circ} 26^{\prime} 4.40^{\prime \prime} \mathrm{E}\end{array}$ & 51.4 & 0.8 & 20 & $10.6-28.4$ & 18.3 & $10.3-27.5$ & 2 sea canal, 3 freshwater inputs \\
\hline
\end{tabular}

on the concave inner side (Fig. 2) and biometric measures were taken with an approximation of $0.01 \mathrm{~mm}$. Images were all coded on a 16-bit RGB scale and captured at high resolution $(2080 \times 1542 \mathrm{pxl})$.

A total of 512 Cartesian coordinates on each otolith contour of the orthogonal projection on the inner side were extracted using Age\& Shape software (V.1.0, Infaimon Software). Elliptic Fourier analysis (EFA) was conducted on these 512 coordinates in order to describe the shape of each otolith. EFA was used to break each profile down into a sum of harmonically related ellipses. The correct number of harmonics was calculated according to Crampton (1995). The Fourier series was truncated for $k=15$, the level at which the average cumulative power is $99.99 \%$ of the average total power (Costa et al., 2009, 2010). According to Rohlf and Archie (1984), the elliptic Fourier coefficients were normalized in order to be invariant with respect to size, location, rotation, and starting position (which was always approximately the tip of the rostrum). EFA and all further analyses were performed in Matlab 7.1 (The Math Works, Natick, USA).

\subsection{Intra-stock analysis}

In order to investigate the occurrence of allometry in the otoliths (size-shape relationship), a Partial Least Squares analysis (PLS) regress EFA coefficients vs observed sizes. PLS is a supervised ordination soft-modelling technique, which allows the construction of predictive morphological models (Wold et al., 2001). The model was used in an exploratory mode to verify a priori the level of correct classification of a data set (multivariate supervised technique). The model works via a specific algorithm (De Jong, 1993) on the whole array of input variables ( $x$-block matrix; i.e.60 EFA harmonic coefficients) and on the observed functional classes or observed values ( $y$-block matrix; i.e. otolith length). The model determines the minimum set of n-estimated latent and score variables via an iterative process, through the initial calculation of maximum correlations. The model includes a calibration

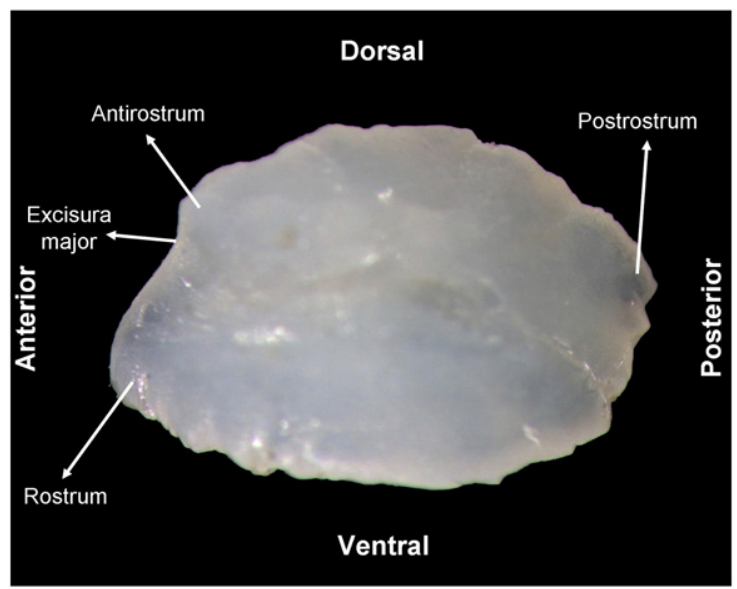

Fig. 2. Otolith glossary. Illustration of the concave side of an eel's right otolith. The anterior and posterior regions are aligned with the orientation of the eel's body. phase and a validation phase, for both of which the percentages of correct classification were calculated. The predictive ability in the test phase also depends on the number of the Latent Variables (LV) used in the model. Generally, the trend of the residual errors is decreasing in the calibration phase (RMSEC) and increasing for the validation phase (RMSECV). The predictive ability in the test phase depends on the number of LV used in the model. Therefore, the model was chosen with a number of LV that ensured the highest value of correlation between predicted and measured which presents the minimum standard error of prediction (SEP) value. All data were pre-processed using the "autoscale" Matlab procedure. The efficiency of extracted PLS model was determined regressing the predicted size with the measured otolith lengths. For each sample site the regression between the first LV and otolith size were represented and the configuration (spline) of the extreme values of the LV axis was extracted using Tpsregr software (Rohlf, 2005).

\subsection{Inter-stock analysis}

Otoliths from the three sampling sites were analyzed in two separate size classes in order to detect any potential differences in otolith shape due to growth. Otoliths were grouped according to major axis length as follows: small $(\mathrm{S} ;<2.2 \mathrm{~mm})$ and large $(\mathrm{L} ;>2.6 \mathrm{~mm})$, eliminating all those remaining within an intermediate range (i.e. $2.3-2.5 \mathrm{~mm}$ ). In this manner, morphological differences were evaluated by extremizing the comparison.

PLS Discriminant Analysis (PLSDA; Sjöström et al., 1986; Sabatier et al., 2003) was used to construct a model explaining the co-variation between otolith shapes, as expressed by EFA coefficients for S and L size classes ( $x$-block), and the different sample sites ( $y$-block). $y$-block classes were represented by a set of dummy variables describing the different samples (for methodological details see Menesatti et al., 2008; Costa et al., 2008, 2010). PLSDA calculates a 'prediction probability' and a classification threshold for each modelled morphological class. These were calculated using a Bayesian method (i.e. the Plsdthres function of Matlab 7.1. PLS toolbox) which takes the predicted $y$-values from the PLSDA model, fits a normal distribution onto them and then uses the results of that fitting to calculate the probability of observation for a given $y$-value. The PLSDA analysis provides the percentage of correct classifications and the loadings of each parameter in each LV. The analysis also calculates the modelling sensitivity (i.e. the percentage of the otoliths of a category accepted by the class model) and specificity (i.e. the percentage of otoliths of the categories differing from the modelled one, rejected by the class model; Aguzzi et al., 2009). The $x$-block values were pre-processed in Matlab 7.1 using the "autoscale" procedure. Each dataset was subdivided into two sub-groups of otoliths: i) $75 \%$ for class modelling and validation; ii) $25 \%$ for the independent test, optimally chosen with the Euclidean distances based on the algorithm of Kennard and Stone (1969). This algorithm was used to select otoliths without any a priori knowledge of a regression model (i.e. on the hypothesis that the true model requires a uniform distribution of objects in the information space; Costa et al., 2008). The calibration models were also validated using a full cross-validation (Venetian blind algorithm) (Matlab 7.1. PLS toolbox). 
A cluster analysis was performed using the complete linkage algorithm on the Euclidean distances calculated from the mean EFA coefficients for each sampling site and size classes. L and S otoliths were considered, thus obtaining six average shapes of otoliths for the sampling sites of the Tiber river (TEV) and the two lagoons, Caprolace (CAP) and Lesina (LES) (i.e. TEV-L, TEV-S, CAP-L, CAP-S, LES-L, and LES-S). The results were visualized by means of a dendrogram in order to compare the relationship between size and site distribution.

\section{Results}

\subsection{Intra-stock analysis}

Otolith lengths predicted by PLS models on EFA coefficients were regressed on the observed lengths. The PLS model correlated significantly with measured lengths producing $R$-test values for the three sampling sites of 0.667 for the Tiber river, 0.886 for the Caprolace lagoon, and 0.771 for the Lesina lagoon (Fig. 3). The statistical parameters of the PLS model indicated a higher performance of classification of the model for the Caprolace samples in terms of standard error of prediction (SEP), root mean square error (RMSE), RMSE of calibration (RMSEC) and RMSE of cross-validation (RMSECV).

The relationship between each observed otolith size and its twodimensional shape, expressed in values of the first and more informative latent vector (LV1) as calculated by the PLS model, is reported for the three sample sites in Fig. 4. By comparing the outlines of shapes corresponding to otoliths at the extreme predicted lengths for each sampling site it is possible to observe some differences within all the samples. In the Tiber sample, otoliths on LV1 presented indeterminate shape differences between the smaller and larger sizes. For both Caprolace and Lesina, on the contrary, otolith shape varied appreciably with increasing size: the sagittae became more elongated with an extension of the rostrum and the postrostrum, while the excisura major became more pronounced.

\subsection{Inter-stock analysis}

PLSDA was carried out on S and L size classes shapes in order to detect any differences in the three sampling sites. The characteristics of models performed on EFA coefficients are reported in Table 3. The most efficient models from otoliths of the $\mathrm{S}$ and $\mathrm{L}$ size classes were based on 9 and 11 Latent Variables (LVs), respectively. Both models presented a high specificity and sensitivity, as well as a low mean classification error. Likewise, the percentage of correct classification of the model was $86.9 \%$ for $\mathrm{S}$ and $88.9 \%$ for $\mathrm{L}$ otoliths. PLSDA model evidenced also a homogeneity in the classification accuracy for each sampling site for both size classes: Small otoliths showed percentage of correct classification of 85.7 at Tiber river, 81.3 at Caprolace lagoon and 7.45 at Lesina lagoon. Large otoliths in the same sampling sites respectively $81.2 \%, 80.0 \%$ and $91.5 \%$. The independent test revealed high values in comparison to random probability. In line with these results, the two models were found to have comparable values of RMSEC.

The cluster analysis on the mean EFA coefficients for otoliths of the $S$ and L size classes showed a clear separation in all sampling sites (Fig. 5). Within the cluster of the $\mathrm{S}$ otoliths, the similarity between the Tiber and Caprolace samples was higher than that reported for both samples compared with Lesina. Conversely, for the otolith L size class, the Caprolace sample showed greater similarity with Lesina than with the Tiber, which clustered more distantly.

\section{Discussion}

In this study we innovatively characterized the occurrence of changes in the morphology of the European eel otolith as a function of growth and the different habitat ecology (a river and two brackish water lagoons). For the first time, the relationship between otolith shape and
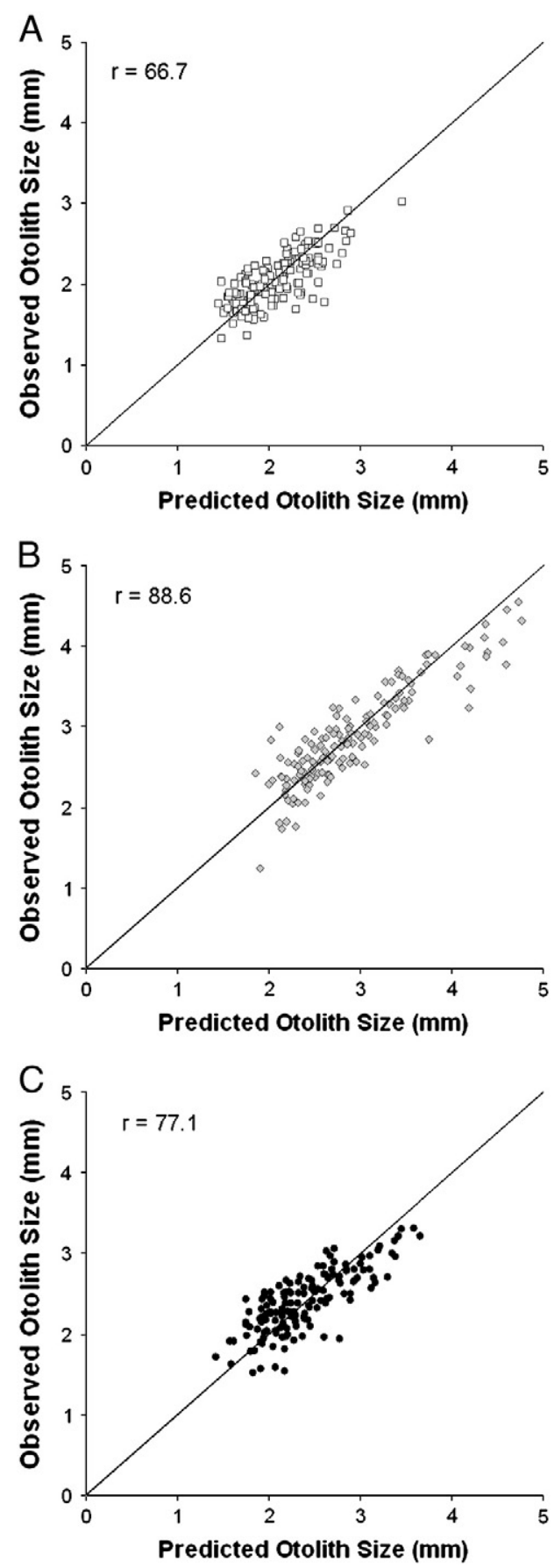

Fig. 3. PLS results. Relationship between measured and PLS predicted otolith sizes for the Tiber river (A), Caprolace lagoon (B) and Lesina lagoon (C) sampling sites.

size was characterized by means of multivariate statistics which allowed the reliable modelling of the eco-morphological variation. According to our results, the shape outline of otolith changes during the ontogenesis, along with the increase in animal size. This modification occurs in a different manner according to the different environments. The result is an otolith shape that is more elongated in appearance and with an accentuation of the protrusions (rostrum and postrostrum) in the two lagoons (Caprolace and Lesina). Conversely, the appearance is less elongated in the Tiber river samples with no evident growth effects. Results thus indicate the presence of a strong reaction norm in otolith shape determination during growth.

Our observations indicate that otoliths are highly uniform in shape at the smaller sizes compared with the larger ones. PLS regression analysis 

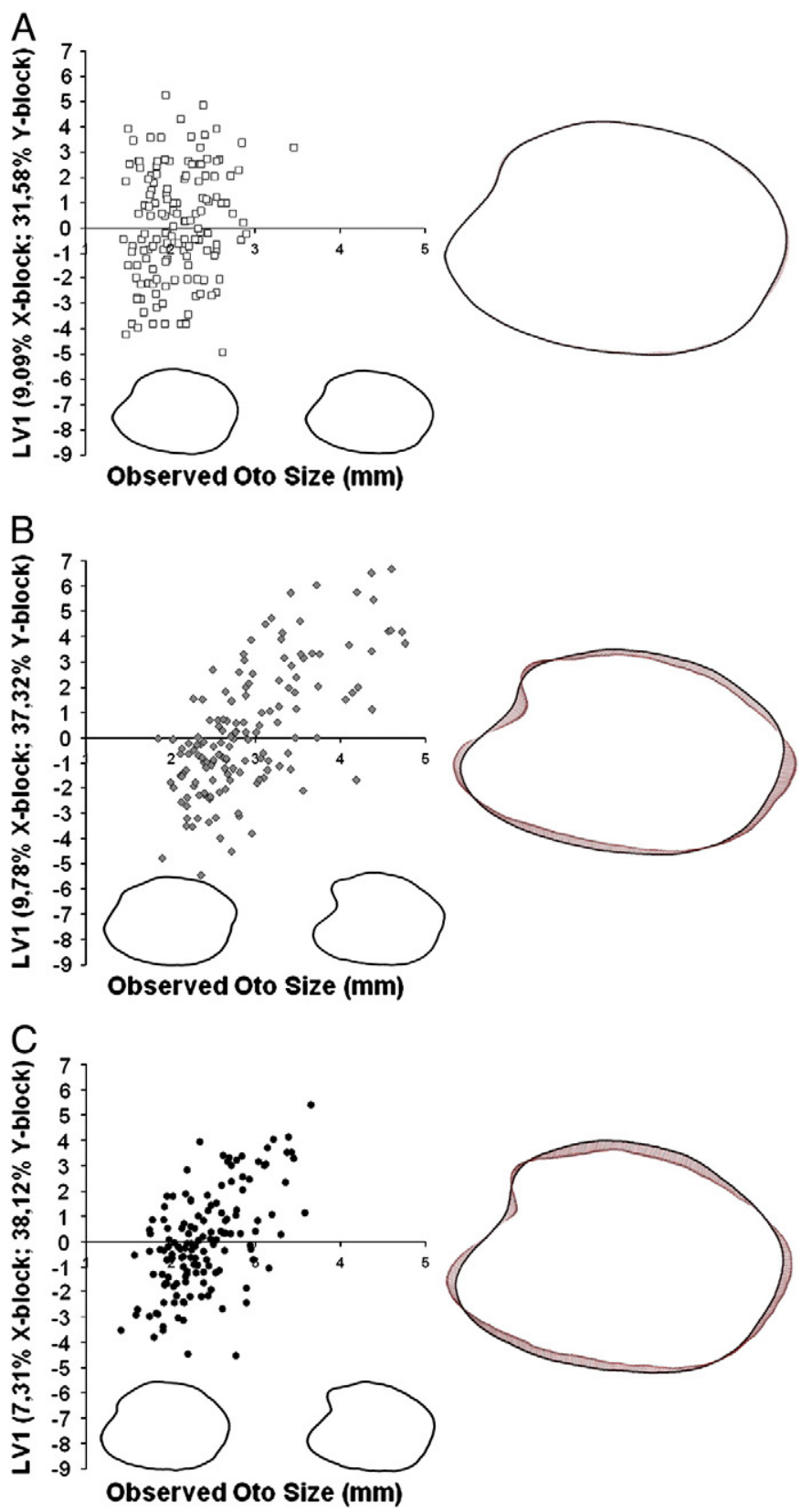

Fig. 4. Shape variation. Relationship between otolith size and the first latent vector (LV1) for each sampling site in PLS analysis for samples taken in the Tiber River (A), Caprolace lagoon (B) and Lesina lagoon (C). The two extreme shape configurations, for smaller (left) and larger (right) otolith, are shown at the bottom of each graph. On the right side of the graphs, the two extreme configurations overlap, showing the areas of wider variation indicated with red vectors.

shows that shape changes occur during otolith growth (see $R$ values in Table 2). This is confirmed by the significant and positive relationship between otolith size and PLS latent vector (LV1; see Fig. 3) bearing the information of the otolith outline characteristics. The PLSDA multivariate technique showed that larger sized otoliths were more efficiently classified by the model than the smaller sized ones in the three different sites considered (see the percentages of correct classification and the high percentages of sensitivity and specificity of Table 3). This confirms the PLS analysis results reported above which indicate that larger otoliths are better classified by the model in the respective environment than those of smaller size.

These data suggest that a differential habitat conditioning necessarily points towards otolith shapes during the later growth stages as a

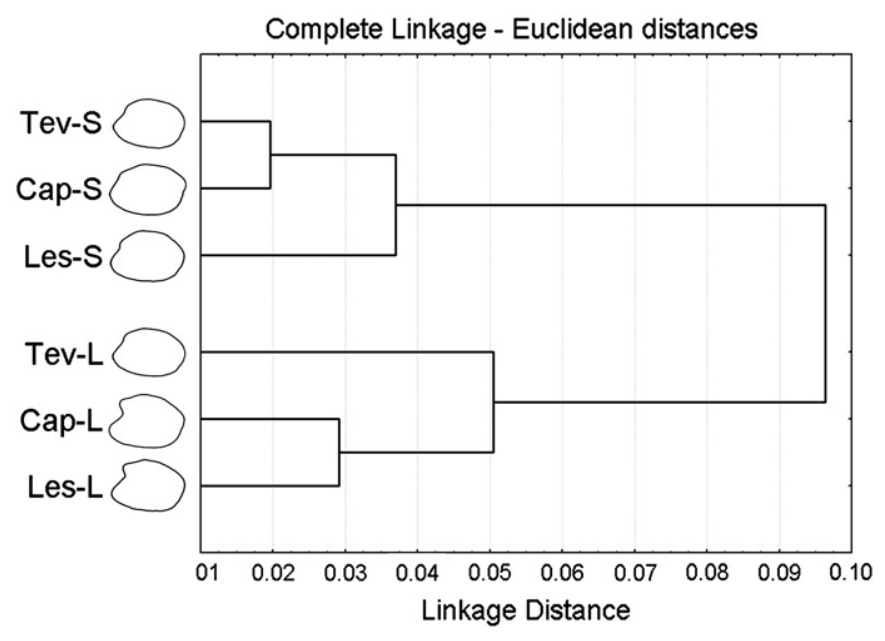

Fig. 5. Cluster analysis. Cluster analysis output depicting the complete linkage dendrogram on Euclidean distances among mean EFA coefficients for larger (L) and smaller (S) otoliths from the three sampling areas of the Tiber River (TEV), Caprolace (CAP) and Lesina lagoons (LES) (see the text for code explanation).

result of a delayed environmental response. Small otoliths probably still maintain a shape similar to that of the post-metamorphic stage, which itself was probably shaped by the marine environment conditions where first the leptocephali and then the glass eels develop (LecomteFiniger, 1992). Following glass eel ascent and colonization of continental waters, eels in the growing phase undergo a differentiation in otolith shape as a result of the local ecological conditions encountered by the eel contingents, namely salinity and temperature that are the influencing factors in other teleostean species (Mosegaard et al., 1988; Cardinale et al., 2004).

Within the large otoliths, the average outlines of the Lesina and Caprolace samples show smaller shape differences with respect to those collected in the Tiber river. As far as the relation between environment conditions and otolith growth of A. anguilla is concerned, our results appear consistent with Panfili et al. (1990) observation of two different types of sagittae, dependent on the width of the growth rings, which they called "brackish water type" and "freshwater type" otolith, respectively. Indeed, the periodicity and the width of the increments due to deposition are regulated by endogenous factors but also depend upon features such as temperature fluctuations and feeding (Campana and Neilson, 1985; Morales-Nin, 2000).

Otoliths from the lagoon specimens studied share a common morphological trend of variation according to growth of the postrostrum and antirostrum with those of other lagoon systems, as in the case of Ebre's Delta (i.e. http://aforo.cmima.csic.es; Lombarte et al., 2006). The specimens collected in the river Tiber are exposed to more homeostatic environmental conditions than those of the two lagoons examined, which

Table 2

PLS characteristics and principal results of the PLS regression models built for the otolith of animals from the three sample sites (Tiber river-TEV; Caprolace lagoon-CAP; Lesina lagoon-LES). See Materials and methods section for explanation of codes.

\begin{tabular}{|c|c|c|c|c|c|c|}
\hline & \multicolumn{2}{|l|}{ TEV } & \multicolumn{2}{|l|}{ CAP } & \multicolumn{2}{|l|}{ LES } \\
\hline & Model & Test & Model & Test & Model & Test \\
\hline$R$ & $80.4 \%$ & $66.7 \%$ & $90.2 \%$ & $88.6 \%$ & $79.2 \%$ & $77.1 \%$ \\
\hline No. latent vectors & 9 & & 10 & & 4 & \\
\hline RMSE & 0.23 & 0.31 & 0.13 & 0.19 & 0.29 & 0.29 \\
\hline RMSEC & 0.23 & & 0.24 & & 0.29 & \\
\hline RMSECV & 0.47 & & 0.44 & & 0.44 & \\
\hline SEP & 0.23 & 0.29 & 0.24 & 0.41 & 0.29 & 0.29 \\
\hline $\begin{array}{l}\text { Total variance } \\
x \text {-block (\%) }\end{array}$ & 45.13 & & 58.39 & & 29.56 & \\
\hline $\begin{array}{l}\text { Total variance } \\
y \text {-block (\%) }\end{array}$ & 64.62 & & 81.44 & & 62.71 & \\
\hline
\end{tabular}


Table 3

PLSDA characteristics and results for both datasets referring to otoliths of the small (S) and (L) size classes.

\begin{tabular}{lcc}
\hline & $\mathrm{S}$ & $\mathrm{L}$ \\
\hline No. individuals ( $x$-block) & 131 & 118 \\
No. of $x$ variables & 57 & 57 \\
No. units ( $y$-block) & 3 & 3 \\
No. LV & 9 & 11 \\
\% cumulated variance $x$-block & 53.46 & 52.64 \\
\% cumulated variance $y$-block & 37.34 & 36.20 \\
Mean specificity (\%) & 91.9 & 90.8 \\
Mean sensitivity (\%) & 86.8 & 92.4 \\
Classification error (\%) & 10.7 & 8.4 \\
Random probability (\%) & 33.0 & 33.0 \\
\% correct classification model & 86.87 & 88.89 \\
No. misclassified (model 75\%) & 15 & 36 \\
\% Correct classification in the independent test & 65.63 & 71.43 \\
\hline
\end{tabular}

are instead exposed to marked daily and seasonal salinity variations (Fabbrocini et al., 2008; Signorini et al., 2008). Salinity is one of the main factors characterizing the ecological niche of Anguilla and hence conditions its growth rate (Sadler, 1979; Cairns et al., 2009; Lamson et al., 2009; Sinha and Jones, 1975). This factor is also involved in otolith growth (Umezawa and Tsukamoto, 1991). Otoliths grow by deposition of incremental layers on the surface (Morales-Nin, 2000). Thus, otolith shape and size are the result of differential growth rates (widths between the growth increments) of each otolith area (Gauldie, 1988, 1993). Consequently, the factors that influence the production rates of growth with increasing temperature also act on the morphology of the whole otolith (Lombarte et al., 2003). The particular abiotic characteristics of the environments occupied by fish can influence otolith growth (MoralesNin, 1987), which is strongly dependent on temperature and depth (Simkiss, 1974; Wilson, 1985). Closely related species or populations from temperate or shallow waters have relatively larger otoliths than those from colder or deeper waters (Gauldie, 1993; Torres et al., 2000).

Cluster analysis (see Fig. 4) indicated that mean profiles, calculated on the EFA coefficients of all smaller otoliths from the Tiber river and Caprolace, are similar, and, are both different in that aspect from the Lesina lagoon samples vis-à-vis the calculated mean profile. These shape differences appear to be related to a variation between glass eel samples respectively from the Tyrrhenian and Adriatic coasts of Italy, itself related to a difference in the condition of metamorphosing larvae and/or newly metamorphosed glass eels and in the time spent in the sea prior to their ascent.

It is generally recognised that differences in length/weight ratio, chemical constitution and energy contents exist among glass eels ascending different inland water areas of Europe at different times during the season (Boëtius and Boëtius, 1989). Differences have also been found in glass eel otoliths growth, as reflected by the radius and width of otolith increments, when comparing animals from different locations (Lecomte-Finiger, 1992). Within this scenario, it is possible that the differences in glass eel otolith shape observed in the present work between Tyrrhenian and Adriatic samples likewise reflect a different condition and a different growth pattern at the postmetamorphic stage in the Mediterranean. Glass eels at completion of metamorphosis possibly split into two contingents, one following the main current system ascending the Tyrrhenian coast and another that finds itself in the current system moving towards the Adriatic Sea. The latter group of eels would spend a different amount of time in marine waters having markedly different physico-chemical characteristics, before colonizing continental habitats.

Otolith growth is not correlated with somatic growth during the anguillid glass eel and elver stage (Fukuda et al., 2009) but is significantly correlated with the development of pigmentation (Poole et al., 2004). The latter represents a chronological record of the individual's history during the anguillid glass eel and elver stage (Strubberg, 1923; Boëtius and Boëtius, 1989; Briand et al., 2005). The discontinuous growth pattern of the otolith during the glass eel stage (McCleave, 2008; Fukuda et al., 2009) may therefore bring about differences in shape. Hence, otolith shape could further enhance our understanding of the post-larval phase of anguillid eels. This is potentially important because fresh evidence indicates that the relative condition of anguillid eels when they ingress inland waters may be decisive in determining their subsequent colonization success (Bureau du Colombier et al., 2007, 2009; Sullivan et al., 2009).

Doering and Ludwig (1990), in the FAbOSA project funded by European Community (FAIR CT97 3402), studied eel otolith shape using the Fast Fourier Transform (FFT) in order to set up a tool of indirect ageing for this species. The proposed shape analysis methodology (EFA), combined with a multivariate approach, represents an innovation in the context of otolith analysis. The drawback of this technique is the need to have a common starting point (reviewed by Capoccioni et al., 2009). From a methodological point of view, the Elliptic Fourier method applied to European eel otoliths affords more efficient shape classification than one selected wavelet (Capoccioni et al., 2009), when data are treated statistically with multivariate tools such as the PLS regression between observed vs predicted otolith lengths.

The approach used in this study, useful in distinguishing between different stocks of many fish species (Torres et al., 2000; Cardinale et al., 2004; Stransky, 2005; Petursdottir et al., 2006), has proven to be reliable also in differentiating local eel stocks, that belong to a single, spatially homogeneous stock insofar as the European eel is a panmittic species (Volckaert et al., 2005; Palm et al., 2009). Our results highlight the role of environmental factors and not only genetic factors in determining the size and shape of fish otoliths. Moreover the application of further analysis to fish characteristics such as age and individual growth rate, makes it possible to interpret the factors that regulate otolith shape.

In conclusion, the present data indicate that the environment probably affects the growth rate and hence the morphology of otoliths. To this end, further studies investigating the relationship at an individual level between microchemical composition, which bears the information of the fish's life history patterns, and otolith shape, will be necessary.

\section{Acknowledgements}

The present work was funded by a grant from the Ministry of Research and University to EC within the PRIN 2006 Project "An Integrated Approach to the Conservation and Management of the European Eel in the Mediterranean Region" (Coordinator Prof. G. De Leo University of Parma); the morphological approach was developed within the framework of the project HIGHVISION (DM 19177/7303/03) to PM. The authors wish to thank the fishermen's associations of the river Tiber, Caprolace and Lesina for their help during samplings. Aguzzi J. is a Postdoctoral Fellow within the Ramon y Cajal Program (MICINN, España). [RH]

\section{References}

Aguzzi, J., Costa, C., Antonucci, F., Company, J.B., Menesatti, P., Sardá, F., 2009. Influence of diel behavior in the morphology of decapod Natantia. Biol. J. Linn. Soc. 96, 517-532.

Begg, G.A., Friedland, K.D., Pearce, J.B., 1999. Stock identification and its role in stock assessment and fisheries management: an overview. Fish. Res. 43, 1-8.

Bevacqua, D., Melia, P., Crivelli, A.J., De Leo, G.A., Gatto, M., 2006. Timing and rate of sexual maturation of European eel in brackish and freshwater environments. J. Fish Biol. 69, 200-208.

Bianchini, M.L., Vaggelli, G., Cossio, R., Palmegiano, G.B., Gai, F., Sola, L., Rossi, A.R., Corsetti, D., Giusto, G.B., Gancitano, S., Ragonese, S., 2009. European eels from deep Mediterranean waters. Am. Fish. Soc. Symp. 69, 871-874.

Boëtius, I., Boëtius, J., 1989. Ascending elvers, Anguilla anguilla, from five European localities. Analyses of pigmentation stages, condition, chemical composition and energy reserves. Dana 7, 1-12.

Briand, C., Fatin, D., Ciccotti, E., Lambert, P., 2005. A stage-structured model to predict the effect of temperature and salinity on glass eel Anguilla anguilla pigmentation development. J. Fish Biol. 67 (4), 993-1009.

Bureau du Colombier, S., Bolliet, V., Lambert, P., Bardonnet, A., 2007. Energy and migratory behavior in glass eels (Anguilla anguilla). Physiol. Behav. 92 (4), 684-690.

Bureau du Colombier, S., Bolliet, V., Bardonnet, A., 2009. Swimming activity and behaviour of European Anguilla anguilla glass eels in response to photoperiod and flow reversal and the role of energy status. J. Fish Biol. 74 (9), 2002-2013. 
Cairns, D.K., Secor, D.A., Morrison, W.E., Hallett, J.A., 2009. Salinity-linked growth in anguillid eels and the paradox of temperate-zone catadromy. J. Fish Biol. 74, 2094-2114.

Campana, S.E., Casselman, J.M., 1993. Stock discrimination using otolith shape analysis. Can. J. Fish. Aquat. Sci. 50 (5), 1062-1083.

Campana, S.E., Neilson, J.D., 1985. Microstructure of fish otoliths. Can. J. Fish. Aquat. Sci. 42 (5), 1014-1032.

Capoccioni, F., Costa, C., Menesatti, P., Lombarte, A., Aguzzi, J., Ciccotti, E., 2009. Otolith growth allometry measurements in the European eel. Instrum. Viewpoint 8, 71-72.

Cardinale, M., Doering-Arjes, P., Kastowsky, M., Mosegaard, H., 2004. Effects of sex stock, and environment on the shape of known-age Atlantic cod (Gadus morhua) otoliths. Can. J. Fish. Aquat. Sci. 61 (2), 158-167.

Castonguay, M., Simard, P., Gagnon, P., 1991. Usefulness of Fourier analysis of otolith shape for Atlantic mackerel (Scomber scombrus) stock discrimination. Can. J. Fish. Aquat. Sci. 48, 296-302.

Costa, C., Aguzzi, J., Menesatti, P., Antonucci, F., Rimatori, V., Mattoccia, M., 2008. Shape analysis of different populations of clams in relation to their geographical structure. J. Zool. 276, 71-80.

Costa, C., Menesatti, P., Paglia, G., Pallottino, F., Aguzzi, J., Rimatori, V., Russo, G., Recupero S., Reforgiato Recupero, G., 2009. Quantitative evaluation of Tarocco sweet orange fruit shape using opto-electronic elliptic Fourier based analysis. Postharvest Biol. Technol. $54,38-47$.

Costa, C., Menesatti, P., Aguzzi, J., D'Andrea, S., Antonucci, F., Rimatori, V., Pallottino, P. Mattoccia, M., 2010. External shape differences between sympatric populations of commercial clams Tapes decussatus and T. philippinarum. Food Bioprocess Technol. 3 (1), 43-48.

Crampton, J.S., 1995. Elliptic Fourier shape analysis of fossil bivalves: some practical considerations. Lethaia 28, 179-186.

Dannewitz, J., Maes, G.E., Johansson, L., Wickström, H., Volckaert, F.A.M., Järvi, T., 2005 Panmixia in the European eel: a matter of time. Proc. R. Soc. Lond. B 272, 1129-1137.

Daverat, F., Tomas, J., Lahaye, M., Palmer, M., Elie, P., 2005. Tracking continental habitat shifts of eels using otolith $\mathrm{Sr} / \mathrm{Ca}$ ratios: validation and application to the coastal, estuarine and riverine eels of the Gironde-Garonne-Dordogne watershed. Mar. Freshwater Res. 56, 619-627.

De Jong, S., 1993. SIMPLS: an alternative approach to partial least squares regression. Chemometr. Intell. Lab. 18 (3), 251-263.

De Leo, G.A., Gatto, M., 1995. A size and age-structured model of the European eel (Anguilla anguilla L). Can. J. Fish. Aquat. Sci. 52, 1351-1367.

Doering, P., Ludwig, J., 1990. Shape analysis of otoliths-a tool for indirect ageing of eel Anguilla anguilla (L.)? Int. Rev. Gesamten Hydrobiol. Hydrogr. 75 (6), 737-743.

Elsdon, T.S., Wells, B.K., Campana, S.E., Gillanders, B.M., Jones, C.M., Limburg, K.E., Secor, D. H., Thorrold, S.R., Walther, B.D., 2008. Otolith chemistry to describe movements and life-history parameters of fishes: hypotheses, assumptions, limitations and inferences. Oceanogr. Mar. Biol. Ann. Rev. 46, 297-330.

Fabbrocini, A., Di Matteo, O., D'Adamo, R., 2008. Abra segmentum (Mollusca: Pelecypoda) of the Lesina Lagoon (Southern Adriatic coast, Italy): observation on variations in the population in relation to the main environmental parameters. Transit. Waters Bull. 1, 39-44.

Fukuda, N., Kuroki, M., Shinoda, A., Yamada, Y., Okamura, A., Aoyama, J., Tsukamoto, K., 2009. Influence of water temperature and feeding regime on otolith growth in Anguilla japonica glass eels and elvers: does otolith growth cease at low temperatures? J. Fish Biol. 74 (9), 1915-1933.

Gauldie, R.W., 1988. Function, form and time-keeping properties of fish otoliths. Comp. Biochem. Phys. 91, 395-402.

Gauldie, R.W., 1993. Continuous and discontinuous growth in the otolith of Macruronus novaezelandiae (Merlucciidae: Teleostei). J. Morphol. 216, 271-294.

Jones, C.M., 1992. Development and application of the otolith increment technique. In Stevenson, D.K., Campana, S.E. (Eds.), Otolith microstructure examination and analysis: Can. Spec. Publ. Fish. Aquat. Sci., 117, pp. 1-11.

Kennard, R.W., Stone, L.A., 1969. Computer aided design of experiment. Technometrics 11 (1), 137-148.

Lamson, H.M., Cairns, D.K., Shiao, J., Iizuka, Y., Tzeng, W., 2009. American eel, Anguilla rostrata, growth in fresh and salt water: implications for conservation and aquaculture. Fish. Manage. Ecol. 16 (4), 306-314.

Lecomte-Finiger, R., 1992. Growth history and age at recruitment of European glass eels (Anguilla anguilla) as revealed by otolith microstructure. Mar. Biol. 114, 205-210.

Lombarte, A., Castellon, A., 1991. Interspecific and intraspecific otolith variability in the genus Merluccius as determined by image analysis. Can. J. Zool. 69 (9), 2442-2449.

Lombarte, A., Torres, G.J., Morales-Nin, B., 2003. Specific Merluccius otolith growth patterns related to phylogenetics and environmental factors. J. Mar. Biol. Ass. U.K. 83, 277-281.

Lombarte, A., Chic, Ô., Parisi-Baradad, V., Olivella, R., Piera, J., García-Ladona, E., 2006. A web-based environment for shape analysis of fish otoliths. The AFORO database. Sci. Mar. 70, 147-152.

McCleave, J.D., 2008. Contrasts between spawning times of Anguilla species estimated from larval sampling at sea and from otolith analysis of recruiting glass eels. Mar. Biol. 155 (3), 249-262.

Melià, P., Bevacqua, D., Crivelli, A.J., Panfili, J., De Leo, G.A., Gatto, M., 2006. Sex differentiation of the European eel in brackish and freshwater environments: a comparative analysis. J. Fish Biol. 69 (4), 876-890.

Menesatti, P., Costa, C., Paglia, G., Pallottino, F., D'Andrea, S., Rimatori, V., Aguzzi, J., 2008 Shape-based methodology for multivariate discrimination among Italian hazelnut cultivars. Biosystems Eng. 101 (4), 417-424.

Morales-Nin, B. 1987. Influence of environmental factors on microstructure of otoliths of three demersal fish species caught off Namibia. In: Payne, A.I.L., Gulland, J.A., Brinkd, K. H. (Eds.), The Benguela and Comparable Ecosystems: S. Afr. J. Mar. Sci., 5, pp. 255-262
Morales-Nin, B., 2000. Review of the growth regulation processes of otolith daily increment formation. Fish. Res. 46, 53-67.

Mosegaard, H., Svedäng, H., Taberman, K., 1988. Uncoupling of somatic and otolith growth rates in arctic char (Salvelinus alpinus) as an effect of differences in temperature response. Can. J. Fish. Aquat. Sci. 45, 1514-1524.

Palm, S., Dannewitz, J., Prestegaard, T., Wickström, H., 2009. Panmixia in European eel revisited: no genetic difference between maturing adults from southern and northern Europe. Heredity 103, 82-89.

Panfili, J., Ximénès, M.C., Do Chi, T., 1990. Age determination of eels in the French Mediterranean lagoons using classical methods and an image analysis system. Int. Rev. Gesamten Hydrobiol. Hydrogr. 75 (6), 745-754.

Petursdottir, G., Begg, G.A., Marteinsdottir, G., 2006. Discrimination between Icelandic cod (Gadus morhua L.) populations from adjacent spawning areas based on otolith growth and shape. Fish. Res. 80 (2-3), 182-189.

Platt, C., Popper, A.N., 1981. Fine structure and function of the ear. In: Tavolga, W.N., Popper, A.N., Fay, R.R. (Eds.), Hearing and sound communication in fishes. SpringerVerlag, New York, pp. 3-38.

Poole, W., Reynolds, J., Moriarty, C., 2004. Early post-larval growth and otolith patterns in the eel Anguilla anguilla. Fish. Res. 66 (1), 107-114.

Prato, S., Morgana, J.G., La Valle, P., Finoia, M.G., Lattanti, L., Nicoletti, L., Ardizzone, G.D., Izzo, G., 2009. Application of biotic and taxonomic distinctness indices in assessing the Ecological Quality Status of two coastal lakes: Caprolace and Fogliano lakes (Central Italy). Ecol. Ind. 9, 568-583.

Rohlf, F.J., 2005. Freeware at. http://life.bio.sunysb.edu/morph/2005

Rohlf, F.J., Archie, J.W., 1984. A comparison of Fourier methods for description of wing shape in mosquitoes (Diptera: Culicidae). Syst. Zool. 33 (3), 302-317.

Sabatier, R., Vivein, M., Amenta, P., 2003. Two approaches for discriminant partial least square. In: Schader, M., et al. (Ed.), Between data science and applied data analysis. Springer, Berlin, Germany.

Sadler, K., 1979. Effects of temperature on the growth and survival of the European eel, Anguilla anguilla L. J. Fish Biol. 15, 499-507.

Sahyoun, R., Claudet, J., Fazio, G., Da Silva, C., Lecomte-Finiger, R., 2008. The otolith as stress indicator of parasitism on European eel. Vie et Milieu 57 (4), 193-200.

Signorini, A., Massini, G., Migliore, G., Tosoni, M., Varrone, C., Izzo, G., 2008. Sediment biogeochemical differences in two pristine Mediterranean coastal lagoons (in Italy) characterized by different phanerogam dominance-a comparative approach. Mar. Freshw. Ecosyst. 18, 27-44.

Simkiss, K., 1974. Calcium metabolism of fish in relation to ageing. In: Bagenal, T.B. (Ed.), Ageing of fish. Unwin Brothers, Old Woking, pp. 1-12.

Sinha, V.R.P., Jones, J.W., 1975. The European freshwater eel. Liverpool University Press, Liverpool, UK.

Sjöström, M., Wold, S., Söderström, B., 1986. PLS discriminant plots. In: Gelsema, E.S., Kanal, L.N. (Eds.), Pattern Recognition in Practice II. Elsevier, Amsterdam, p. 486.

SOGESID, 2002. Attività connesse alla redazione del piano di tutela delle acque: relazione generale. Regione Puglia - Commissario delegato per l'emergenza ambientale presidente della regione Puglia - Ordinanza del Ministro dell'Interno n 3184 del $22 / 3 / 2002$

Solimini, A.G., Gulia, P., Monfrinotti, M., Carchini, G., 2000. Performance of different biotic indices and sampling methods in assessing water quality in the lowland stretch of the Tiber River. Hydrobiologia 422 (423), 197-208.

Stransky, C., 2005. Geographic variation of golden redfish (Sebastes marinus) and deep-sea redfish (S. mentella) in the North Atlantic based on otolith shape analysis. ICES J. Mar. Sci. 62 (8), 1691-1698.

Stransky, C., Garbe-Schönberg, C.D., Günther, D., 2005. Geographic variation and juvenile migration in Atlantic redfish inferred from otolith microchemistry. Mar. Freshw. Res. 56, 677-691.

Strubberg, A.C., 1923. Elvers from North and South Europe. Rep. Dan. Oceanog. Esplor. 3, 1-29 (1908-1910)

Sullivan, M.C., Wuenschel, M.J., Able, K.W., 2009. Inter and intra-estuary variability in ingress, condition and settlement of the American eel, Anguilla rostrata: implications for estimating and understanding recruitment. J. Fish Biol. 74 (9), 1949-1969.

Torres, G.J., Lombarte, A., Morales-Nin, B., 2000. Sagittal otolith size and shape variability to identify geographical intraspecific differences in three species of the genus Merluccius. J. Mar. Biol. Ass. U.K. 80, 333-342.

Tzeng, W.N., Severin, K.P., Wickström, H., 1997. Use of otolith microchemistry to investigate the environmental history of European eel Anguilla anguilla. Mar. Ecol. Prog. Ser. 149 (1-3), 73-81.

Tzeng, W.N., Severin, K.P., Wang, C.H., Wickström, H., 2005. Elemental composition of otoliths as a discriminator of life stage and growth habitat of the European eel, Anguilla anguilla. Mar. Freshw. Res. 56, 629-635.

Umezawa, A., Tsukamoto, K., 1991. Factors influencing otolith increment formation in Japanese eel, Anguilla japonica. J. Fish Biol. 39, 211-223.

Volckaert, F.A.M., Dannewitz, J., Maes, G.E., Johansson, L., Wickström, H., Järvi, T., 2005. Panmixia in the European eel: a matter of time. Proc. R. Soc. Lond. B 272, 1129-1137.

Vøllestad, L.A., 1992. Geographic variation in age and length at metamorphosis of maturing European eel: environmental effects and phenotypic plasticity. J. Anim. Ecol. 61 (1), 41-48.

Wilson Jr., R.R., 1985. Depth-related changes in sagitta morphology in six macrourid fishes of the Pacific and Atlantic Oceans. Copeia 4, 1011-1017.

Wirth, T., Bernatchez, L., 2001. Genetic evidence against panmixia in the European eel. Nature 409, 1037-1040.

Wold, S., Sjostrom, M., Eriksson, L., 2001. PLS-regression: a basic tool of chemometrics. Chemometr. Intell. Lab. 58 (2), 109-130. 